\title{
Global existence and nonexistence of solutions to the Cahn-Hilliard equation with variable exponent sources
}

\author{
Van Chuong Quach ${ }^{1}$, Le Nhan ${ }^{2}$, and Truong $\mathrm{Le}^{3}$ \\ ${ }^{1}$ Dong Nai University \\ ${ }^{2}$ Ho Chi Minh City University of Technology and Education \\ ${ }^{3}$ University of Economics Ho Chinh Minh City
}

May 6, 2020

\begin{abstract}
This paper deals with a Cahn-Hilliard equation with variable exponent sources. By using the potential well method, we give some threshold results on existence and nonexistence of global weak solutions when initial data with energy less than the potential well depth $\$ \mathrm{~d} \$$. In the former case, we also show the exponential decay properties of energy functional. We finally obtain some sufficient conditions for the global existence and non-global existence results with high energy initial data. The results of this paper extend some recent results of Han (2018) (missing citation) and Zhou (2019) (missing citation) to the case of PDEs with variable exponent sources.

\section{Hosted file}

ChNhTruong_April-29-20.pdf available at https://authorea.com/users/317555/articles/447616global-existence-and-nonexistence-of-solutions-to-the-cahn-hilliard-equation-withvariable-exponent-sources
\end{abstract}

\section{References}

